\title{
A exigência de uma abordagem interdisciplinar no crime de abuso sexual de pessoa incapaz de resistência praticado contra indivíduos com deficiência intelectual
}

https://doi.org/10.21814/uminho.ed.30.23

\author{
Maria João Lourenço \\ Doutoranda em Ciências Jurídicas na Escola de Direito da \\ Universidade do Minho \\ Assistente Convidada da Escola de Direito da \\ Universidade do Minho
}

\section{Notas introdutórias}

Está no dia de hoje a terminar a Presidência Portuguesa do Conselho da União Europeia no $1 .^{\circ}$ semestre de 2021 . De entre as prioridades e linhas de ação que a nortearam, destacou-se uma preocupação com a necessidade (diríamos premente) de prevenção e proteção dos cidadãos e dos seus direitos, liberdades e garantias e, em especial, das maiores necessidades e dificuldades na defesa dos direitos e acesso à justiça pelos adultos vulneráveis ${ }^{1}$. Dando seguimento a esse ensejo, realizou-se no dia 30 de março de 2021 a Conferência de Alto Nível subordinada ao tema "A Proteção de Adultos Vulneráveis na Europa - o Caminho a Seguir"'. Investigadores e agentes políticos fizeram notar que já foi percorrido um importante caminho, mas reconheceram que os resultados alcançados não são satisfatórios porque não se mostra alcançada, a nível igualitário, a proteção dos direitos das pessoas vulneráveis, que continuam a deparar-se com sérios obstáculos no acesso à justiça.

Porque excederia os limites da nossa contribuição uma análise do longo caminho já percorrido e daquele que haverá ainda a percorrer ${ }^{3}$, decidimos cingir a nossa reflexão a um tipo particular de situações que nos parece bem evidenciar as dificuldades sentidas. Referimo-nos às situações de abuso sexual de pessoa portadora de transtorno

1 Vd. Portugal - Programa da Presidência Portuguesa do Conselho da União Europeia, disponível em https://infoeuropa.eurocid.pt/registo/000085448 [31.03.2021].

2 A conferência pode ser visualizada no seguinte endereço https://www.youtube.com/ watch?v=v9zD1vLRt90\&t=9s.

3 Para uma compreensão do trabalho desenvolvido pela UE sobre a temática, pode ler-se FRA - Fundamental Rights Report 2020, disponível em https://fra.europa.eu/en/publication/2020/fundamental-rights-report-2020. 
do desenvolvimento intelectual (vulgo deficiência intelectual) ${ }^{4}$. Começando por analisar a especial vulnerabilidade destas vítimas, procuraremos explicar os obstáculos com os quais estas se deparam no acesso à justiça e as dificuldades inerentes ao respetivo processo judicial. Terminaremos apontando algumas medidas que nos parecem adequadas a seguir no caminho que ainda se mostra longo e que aos nossos olhos terá que ser percorrido por uma calçada interdisciplinar.

\section{A especial vulnerabilidade das pessoas portadoras de deficiência intelectual e as suas dificuldades no acesso à justiça}

De acordo com o relatório elaborado pela Associação Portuguesa de Apoio à Vítima tendo por referência o ano de 2019, foram abertos no sistema judicial seis processos-crime por abuso sexual de pessoa incapaz, representando 0,02\% da totalidade dos crimes registados ${ }^{5}$. Estima-se, contudo, que apenas 3\% dos casos de abuso sexual contra pessoas portadoras de deficiência intelectual seja reportado ${ }^{6}$ e que a prevalência deste crime relativamente a estas vítimas seja de quatro a dez vezes superior à da população em geral' ${ }^{7}$. Estes números não têm, contudo, reflexo nas estatísticas oficiais ou na literatura que parecem permanecer à margem da realidade.

Apesar de em reduzido número, alguns dos estudos desenvolvidos sobre a temática procuraram aferir os motivos pelos quais apenas um número tão reduzido de casos de abuso sexual é reportado às autoridades competentes. As razões apuradas prendem-se com as dificuldades destas vítimas na comunicação e na compreensão da realidade que as rodeia, mas também com o facto de se mostrarem dependentes

4 Cf. AMERICAN PSYCHIATRIC ASSOCIATION - DSM-5: Manual de Diagnóstico e Estatístico das Perturbações Mentais. $5^{a}$ Edição. Lisboa: Climepsi Editores, 2014. ISBN 9789727963478. Sugere-se a leitura deste manual para conhecimento das patologias caraterizadoras dos diferentes graus e condições cognitivas dos indivíduos diagnosticados com este tipo de transtorno.

5 Cf. ASSOCIAÇÃO PORTUGUESA DE APOIO À VÍTIMA - Estatísticas APAV: relatório anual 2019 [Em linha]. Lisboa: APAV, 2020 [18.02.2021]. Disponível em https://apav.pt/apav_v3/images/pdf/Estatisticas_APAV-Relatorio_Anual_2019.pdf.

6 Cf. VALENTI-HEIN, D.; SCHWARTZ, L. apud CHAVE-COX, Rebecca S. - Forensic examination of the mentally disabled sexual abuse complainant, "Journal of Forensic and Legal Medicine" [Em linha]. ISSN 1878-7487. Vol. 25 (2014), pp. 71-75 [23.02.2021]. Disponível em https://pubmed.ncbi.nlm.nih.gov/24931867, p. 72.

7 Cf. MORANO, Jamie. P. - Sexual abuse of the mentally retarded patient: medical and legal analysis for the primary care physician, "Primary care companion to the Journal of clinical psychiatry" [Em linha]. ISSN 2155-7780. No 3 (2003), pp. 126-135 [23.02.2021]. Disponível em https://pubmed.ncbi.nlm.nih. gov/15014610/, p. 130. Para uma compreensão dos fatores que justificam esta maior incidência dos crimes sexuais em pessoas com deficiência intelectual podem ler-se, entre outros, CHAVE-COX, Rebecca S. - op. cit.; ZAVIRŠEK, Darja - Pictures and silences: memories of sexual abuse of disabled people, "International journal of social welfare" [Em linha]. ISSN 1468-2397. Vol. 11, n 4 (2002), pp. 270-285. [23.02.2021]. Disponível em https://onlinelibrary.wiley.com/doi/abs/10.1111/1468239700237; MACHADO, Carla - Avaliação de alegações de abuso sexual de pessoas com deficiência mental, “Psychologica”. Coimbra. ISSN 0871-4657. N 48 (2008), pp. 293-315, p. 295 e MURPHY, Glynis H. - Capacity to consent to sexual relationships in adults with learning disabilities, "Journal of Family Planning and Reproductive Health Care" [Em linha]. ISSN 2045-2098. N 29 (2003), pp. 148-149 [23.02.2021]. Disponível em https://pubmed.ncbi.nlm.nih.gov/12885309. 
de terceiros para denunciar os crimes (os quais por vezes são os próprios abusadores), ou de se terem que deslocar às instalações das entidades competentes para receber a denúncia e nem sempre disporem de condições para o fazer (físicas, económicas e/ou logísticas), ou ainda por desconhecerem ou não compreenderem o procedimento que devem seguir para dar início ao processo judicial. A par de tudo isto, o formalismo de um processo judicial, com tramitação morosa, linguagem técnica e inúmeras diligências, constitui um fardo que muito poucos parecem estar dispostos ou têm condições de suportar.

Por contraste com esta realidade, os estudos desenvolvidos pela Agência dos Direitos Fundamentais da União Europeia (FRA) permitiram concluir que as vítimas vulneráveis ${ }^{8}$ manifestaram maior interesse e necessidade em participar nos processos de natureza criminal do que as demais. Apesar disso, estas vítimas mostraram-se mais céticas relativamente à forma pela qual os seus direitos são assegurados pelo sistema e ao empenho com que a polícia emprega na investigação dos crimes de que são vítimas. A conclusão que a FRA extraiu é tão evidente quanto preocupante: se o número reduzido de vítimas que denuncia os crimes contra si praticados não sentir que no final do processo foi realizada justiça, deixarão de denunciar futuros crimes. E se o acesso à justiça já se mostra frágil, deixa depois de existir.

Este mostra-se, pois, um flagelo à escala global. Um flagelo que exige uma resposta urgente porque o confronto entre os estudos empíricos e os dados oficiais provam que, além de particularmente vulneráveis, estas são também vítimas silenciadas e esquecidas pelo nosso sistema judicial. Cremos que esta resposta apenas pode ser apresentada depois de compreendidas as múltiplas dimensões do fenómeno. Uma compreensão que necessariamente deve ser multidisciplinar, convocando estudos especializados (pelo menos) nas áreas do Direito, da Criminologia, da Psicologia, da Sociologia e da Medicina. Um estudo interdisciplinar que deve orientar a adotação de medidas preventivas, mas que deve nortear também a condução dos processos judiciais.

\section{Exigências de uma abordagem interdisciplinar na definição de medidas preventivas}

A título preventivo, parece-nos que uma visão interdisciplinar seria sempre necessária e essencial para delinear planos de mediatização deste tipo de criminalidade e de educação das pessoas portadoras de deficiência intelectual, dos seus educadores e familiares para a temática da sexualidade e do abuso?.

8 Trata-se, naturalmente, de um grupo mais abrangente de pessoas do que apenas que são objeto do nosso estudo, mas julgamos ser relevante a referência pelo facto de estas conclusões refletirem também as necessidades dos portadores de deficiência intelectual. Assista-se à conferência a que se fez alusão na nota de rodapé $n .^{\circ} 2$.

9 Alguns autores que se dedicaram a estudar a problemática de uma perspetiva sociológica e psicológica referem que a educação sexual das pessoas portadoras de deficiência será um dos pilares mais importantes no combate a esta criminalidade - cf. MURPHY, Glynis H. - op. cit. 
Uma visão interdisciplinar também na sensibilização das pessoas e entidades que se mostram mais próximas destas vítimas (como familiares, médios, psicólogos, assistentes socais, educadores,....) para as consciencializar desta realidade e do importante papel que podem desempenhar na prevenção e no reporte de casos de abuso sexual de pessoas com deficiência intelectual.

Para definição e concretização desses planos, deveriam assumir particular relevo profissionais das áreas da Criminologia, da Psicologia, da Sociologia e da Medicina, cujo trabalho conjunto permitiria melhor identificar nosso plano geográfico a real dimensão deste tipo de crime e incentivar o reporte às instâncias competentes, mas também permitiria consciencializar as vítimas de comportamentos abusivos que muitas vezes desconhecem enquanto tal e chamar atenção à comunidade em geral para necessidade de combate e prevenção deste fenómeno.

\section{Exigências de uma visão interdisciplinar no ato de decisão}

\subsection{O estado atual}

Para lá das importantes medidas preventivas que podem ser tomadas, outras se impõem adotar no âmbito dos processos judiciais para prevenir que a própria tramitação do processo seja fator inibidor de reporte de situações abusivas contra pessoas com deficiência intelectual. Isto porque, como vimos, o formalismo processual e a incompreensão pelo sistema destas vítimas afasta a sua participação efetiva. Note-se que já em 2016 o Comité dos Direitos das Pessoas com Deficiência da ONU recomendou a Portugal que, em matéria penal, fosse pensada legislação que assegurasse em pela igualdade o acesso à justiça entre todos os cidadãos, mormente os que padecem de algum tipo de deficiência. O Comité recomendou ainda que, em matéria de violência doméstica, fossem desenvolvidas estratégias e programas para prevenir a exploração, violência e abuso e fortalecidas medidas, incluindo capacitação dos serviços de investigação e magistrados, para proteger as pessoas com deficiência, especialmente mulheres e crianças $^{10}$.

De lá para cá parece pouco ter sido feito a este respeito. Aliás, ainda em março deste ano a Comissão Europeia reconheceu na estratégia sobre os Direitos das Pessoas com Deficiência para 2021-2030 que se verificam um conjunto de obstáculos práticos e jurídicos que impedem as pessoas com deficiência de agir como testemunhas em processos penais e civis, de defender os seus direitos enquanto vítimas, suspeitos

10 Cf. COMISSÃO SOBRE OS DIREITOS DAS PESSOAS COM DEFICIÊNCIA - Observações finais sobre o relatório inicial de Portugal [Em linha]. S.l., abril de 2016 [05.05.2021]. Disponível em http://oddh.iscsp.ulisboa. pt/index.php/pt/2013-04-24-18-50-23/outras-publicacoes/item/276-recomenda\%C3\%A7\%C3\%B5es-da-onu-a-portugal-sobre-direitos-das-pessoas-com-defici\%C3\%AAncia. 
ou arguidos, e também de participar em capacidades profissionais como juízes, advogados e procuradores ${ }^{11}$.

Julgamos serem estas as estratégias que se relevarão no futuro verdadeiramente eficazes. Aliás, estas preocupações já se mostram espelhadas em diversos diplomas nacionais e internacionais. A título exemplificativo, a Lei n. ${ }^{\circ}$ 130/2015, de 04 de setembro, transpondo uma Diretiva da União Europeia que estabelece (diríamos nós, standards mínimos de) apoio e proteção das vítimas de criminalidade, transparece preocupações com a necessidade de prevenir a vitimização secundária, consagrando um direito a uma participação ativa no processo e exigindo esforços às diversas entidades para estabelecer uma comunicação que seja compreendida pela vítima, bem assim como a possibilidade de esta ser assistida por pessoa da sua confiança no primeiro contacto com as autoridades competentes ou até por patrono.

Parece-nos, contudo, que a barreira ao acesso à justiça se verifica no plano prático e é no dia-a-dia que os diversos atores do sistema judicial se deparam com inúmeras dificuldades em assegurar estes direitos sobretudo quando as vítimas apresentam quadros de deficiência intelectual mais graves.

Entendemos que se justificam as preocupações de dotar o sistema de meios humanos e materiais (tão necessários que são) para alargar o acesso da justiça a estas vítimas. Mas julgamos que o que está em maior falta é a capacitação dos diferentes profissionais para lidarem com este tipo de situações.

Entre muitos outros exemplos que poderíamos aqui referir e de entre muitas outras preocupações para as quais aqui poderíamos chamar atenção que demonstram as dificuldades sentidas neste acesso efetivo e igualitário, trazemos ao conhecimento uma decisão judicial que nos deixou particularmente incomodados ${ }^{12}$. Em causa, uma decisão do Tribunal da Relação de Lisboa que revogou a condenação de um arguido condenado pela prática de ato sexual contra pessoa com síndrome demencial, normalmente apática e apenas esporadicamente verbalizando palavras, mas sensível à dor, no pagamento de uma indemnização pelo crime por si praticado por não resultarem provados danos morais decorrentes desse abuso. 0 Tribunal de $1 .^{a}$ instância havia condenado o arguido no pagamento de uma indemnização por considerar que tais danos morais sempre decorreriam diretamente da atuação ilícita do arguido e traduziram-se "na violação dolosa de um feixe de direitos de personalidade da ofendida, onde pontifica a sua dignidade, mas também a sua liberdade, a honra, a privacidade, a intimidade, a saúde e a integridade física". Na posição assumida pelo Tribunal de 1. ${ }^{a}$ instância, "[a] circunstância demente em que se encontra[va] [a vítima] não a destitui[ía] desses direitos, pelo contrário, torna[va] a sua tutela ainda mais necessária". A 2. instância julgou que, não vigorando entre nós uma conceção objetiva de

11 Cf. COMISSÃO EUROPEIA - União da Igualdade: Estratégia sobre os Direitos das Pessoas com Deficiência 2021-2030 [Em linha]. Bruxelas, março de 2021 [07.05.2021]. Disponível em https://ec.europa.eu/ social/main.jsp?catld=738\&langld=pt \&publd=8376\&furtherPubs=yes.

12 Cf. acórdão proferido pelo Supremo Tribunal de Justiça em 14.03.2018 no processo que correu os seus termos sob o n. ${ }^{\circ}$ 191/09.5PEPDL.L4.S1 [07.05.2021]. Disponível em www.dgsi.pt. 
danos e não tendo resultado provado um prejuízo sofrido pela vítima, o pedido de indemnização teria necessariamente que ser improcedente.

Estamos em crer que esta decisão permitirá ao leitor compreender o sentimento de injustiça referido em muitos dos depoimentos que a FRA recolheu aquando dos trabalhos desenvolvidos sobre as dificuldades de acesso à justiça por pessoas vulneráveis. Julgamos infeliz a posição da 2. ${ }^{a}$ instância, que parece ter sido tomada em desconsideração do quadro cognitivo da vítima que, comprovadamente, a impediria de manifestar qualquer tipo de sentimento ou dano sofrido pelo abuso sexual contra si praticado ${ }^{13}$.

Rejeitar uma indemnização pela sua incapacidade de verbalizar, quando ficou provado que a vítima era sensível à dor, transparece a fragilidade em que estas vítimas se encontram perante o sistema judicial. Mas prova também as dificuldades de compreensão do sistema relativamente a estas vítimas, para as quais muitas vezes olha, infundadamente, com o preconceito de serem vítimas pouco credíveis, dificultando ou impedindo por isso a sua participação na investigação e no processo. Neste ponto não podemos deixar de lembrar que estamos perante vítimas que apresentam um quadro com perturbações ao nível do funcionamento intelectual acompanhado de défices funcionais, que se manifesta habitualmente em dificuldades associadas à avaliação de riscos, de autocontrolo do comportamento, de emoções ou de relações interpessoais. Vítimas que podem ver afetadas as suas capacidades de comunicação e compreensão. Vítimas que por vezes sofrem de uma predisposição à adoção de comportamentos disruptivos ou agressivos. Vítimas que não raras vezes apresentam dificuldades de memória, de concentração, de distinção entre verdade e falsidade e de realidade e fantasia. Vítimas que, por tudo isto, são vistas como pouco credíveis. Mas este é um lugar-comum que merece ser revisitado. Não é em virtude da deficiência intelectual que estas vítimas podem ser esquecidas ou sequer que lhes pode ser negado ou prejudicado um direito reconhecido aos demais. Julgamos que o seu direito à participação deve ser reconhecido, permitido e incentivado, ainda que adstrito ao respetivo quadro cognitivo.

É precisamente esta participação que exige a capacitação dos profissionais que atuam no sistema judicial. Em primeiro lugar, dos agentes dos órgãos de polícia criminal que muitas vezes são os primeiros a ter contacto com as vítimas e que desenvolvem toda a investigação, na qual necessariamente terão que contactar com a vítima e com os seus familiares. Depois, dos próprios advogados que terão o importante papel de agente da justiça junto da vítima, aos quais compete um acompanhamento muito próximo assente numa base de confiança e compreensão mútuas. Mas também, e sobretudo, dos magistrados que não só têm um papel ativo no desfecho

13 Não podemos concordar com esta decisão e louvamos a decisão do Supremo Tribunal de Justiça que, invocando princípios arreigados na dignidade da pessoa humana, fez notar que estas vítimas, sendo especialmente vulneráveis, carecem de maior proteção e revogou a decisão da $2 .^{a}{ }^{\text {instância. Proferindo }}$ um acórdão com forte pendor axiológico, sublinhou este Supremo Tribunal que as pessoas portadoras de deficiência intelectual não podem ser vítimas de capitis diminutio. e concluiu então que, resultando provada a ilicitude do ato, deveria ficar assente, nesta situação, a verificação do dano. 
dos processos, como também têm que definir estratégias adequadas para audição e participação destas vítimas. Que estratégias devem ser seguidas para esta capacitação é o que procuramos apontar de seguida.

\subsection{Rumos a seguir}

A literatura sobre o tema que aqui refletimos é parca e dispersa. Aliás, aquela que tem vindo a ser mais incidente é produzida não por juristas, mas por profissionais da saúde mental. São sobretudo estes profissionais que chamam atenção para as dificuldades de uma participação ativa no processo e para o sentimento de impotência destas vítimas. Procurando partir dos apelos feitos por estes profissionais, apresentamos de seguida alguns aspetos que julgamos merecem maior cuidado aquando da participação processual destas vítimas.

Em termos logísticos, será necessário dotar os Tribunais e os locais onde são recebidas as vítimas e seus familiares de salas adequadas à sua audição. As salas devem permitir maior privacidade e estarem equipadas com material lúdico para que as vítimas possam expressar-se com recurso a diferentes tipos de comunicação (p. ex., através de desenho ou de bonecos anatómicos) ${ }^{14}$. A pessoa que recolhe o depoimento da vítima deverá ser do mesmo género para permitir uma maior proximidade e à vontade aquando da recolha do depoimento e caso seja necessário ouvir a vítima por diversas vezes, será importante que seja sempre a mesma pessoa a recolher o seu depoimento.

No processo de recolha do depoimento, deve ser privilegiada maior informalidade e a utilização de linguagem mais simples e/ou linguagem não verbal adequada ao funcionamento cognitivo do indivíduo e ao seu funcionamento real nos vários contextos da vida. Pode ainda mostrar-se importante a nomeação de intérprete, técnico ou perito para acompanhar as diligências quando se mostre necessária a sua participação para assegurar uma compreensão mútua entre a entidade que recolhe o depoimento e a vítima. Eventualmente até pode ser admissível que a vítima seja acompanhada por pessoa da sua confiança caso tal se mostre relevante para prestar o seu depoimento ${ }^{15}$. Também o tipo de questões a colocar deve ser ajustado, devendo preferir-se narrativas abertas durante as quais podem ser colocadas, alternadamente, questões abertas e fechadas, ao invés de questões sugestivas ou de resposta monossilábica e especiais exigências são ainda feitas relativamente à interpretação da linguagem não verbal, exigindo-se que a pessoa que está a ouvir a vítima disponha de ferramentas e conhecimentos para conseguir interpretar, p. ex., sinais de cansaço ou de fragilidade emocional provocados pela abordagem de algum assunto.

14 Muito recentemente surgiram recomendações neste sentido pela Assembleia da República a respeito da participação das crianças nos processos judiciais - vf. Resolução da Assembleia da República n. ${ }^{0} 118 / 2021$, publicada no DR n. ${ }^{\circ} 76 / 2021$, de 20.04.2021. De fora destas recomendações ficaram, entre outas, as pessoas portadoras de deficiência intelectual.

15 Cf. a nota de rodapé anterior. 
É ainda claro que esta audição da vítima e a sua participação ativa no processo apenas pode ser assegurada quando se afigure que a vítima dispõe de capacidade para testemunhar e que o seu testemunho se mostre credível. Precisamente por isso, mostra-se ainda importante que antes da participação da vítima seja ordenada realização de perícia psicológica para conhecimento do seu quadro cognitivo. Esta perícia, além de permitir descrever tal quadro, permitirá fazer uma avaliação da capacidade de testemunho da vítima e da credibilidade das declarações por si prestadas. Note-se que estas avaliações carecem de especiais conhecimentos de que o Tribunal não dispõe e por isso nesta sede será indispensável que o Tribunal ordene a realização de perícia de psicologia forense tendente a tais objetivos. A perícia não se mostra simples e os profissionais têm chamado atenção para o facto de não existir um quadro metodológico pré-estabelecido especificamente para estas situações, apelando a uma adaptação do tipo de entrevistas que são realizadas nas situações de suspeitas de abuso sexual de crianças de tenra idade, adaptando esse modelo às idiossincrasias de cada uma destas vítimas (designadamente do seu quadro cognitivo e dos conhecimentos que demonstrem ter sobre situações abusivas ${ }^{16}$. Esta perícia pode mostrar-se ainda um importante meio de prova quando é realizada e valorada conjuntamente com uma perícia de sexologia forense para a avaliação das alegações de abuso (i.e. para averiguar se a vítima terá ou não prestado o seu consentimento ou se estava em condições de formar e/ou exprimir a sua vontade relativamente ao ato) e para avaliação dos danos sofridos em virtude do abuso sexual. Nestas duas situações, as declarações da vítima podem (e devem) ser complementadas e confrontadas com as conclusões da perícia de sexologia forense, que assim constitui um importante elemento de que o psicólogo poderá lançar mão aquando da avaliação da credibilidade das declarações da vítima. Deste modo, estas perícias devem ser ordenadas conjuntamente e realizadas numa perspetiva multi e interdisciplinar ${ }^{17}$. Situação que é distinta daquela que habitualmente temos: realização de duas perícias isoladas e valoradas separadamente. Note-se que até para a própria vítima a presença de uma pessoa que já conhece e com quem já estabeleceu uma relação de confiança (como se espera que aconteça com o psicólogo que desempenha a função de perito) pode facilitar a realização da perícia de sexologia forense.

Esta visão multi e interdisciplinar deve também ser transversal aos médicos e psicólogos que, ao atuarem como peritos nestes processos, não estão dispensados de conhecer os limites da sua atuação nessa qualidade. A acrescer, também eles, como clínicos, se deparam com um conjunto de dificuldades aquando da realização das

16 Cf., a respeito, MACHADO, Carla; CARIDADE, Sónia; ANTUNES, Carla - Avaliação psicológica de vítimas de abuso sexual, in Marlene Matos, Rui Abrunhosa Gonçalves e Carla Machado (coord) - "Manual de Psicologia Forense: contextos, práticas e desafios”. Braga: Psiquilíbrios Edições, 2011. ISBN 978-989-8333-07-0, pp. 91-122 e MACHADO, Carla - Avaliação de alegações de abuso sexual de pessoas com deficiência mental, op. cit..

17 Até porque se pensarmos que a perícia de sexologia forense se inicia com uma entrevista à vítima para que esta relate os acontecimentos de maneira a que o perito adeque os atos à situação, facilmente se compreende que antes disse deve ser feita avaliação por um psicólogo sobre a capacidade de testemunhar da vítima e a credibilidade as suas declarações - COSTA, Diogo Paulo Lobo Machado Pinto da - A perícia médico-legal nos crimes sexuais [Em linha]. Porto: Universidade do Porto, 2000. [10.02.2020]. Disponível em https://sigarra.up.pt/fmup/pt/ucurr_geral.ficha_uc_view?pv_ocorrencia_id=400542. 
perícias e necessitam de uma avaliação interdisciplinar para melhor avaliação. De facto, se se mostra necessário a avaliação da capacidade de testemunho e de credibilidade antes de realização da perícia de sexologia forense, certo é que uma avaliação das alegações de abuso e da extensão dos danos dele decorrentes também só se mostrará completa com os resultados da perícia de sexologia.

\section{Notas conclusivas}

O fenómeno sobre o qual nos debruçamos mostra-se um flagelo à escala mundial. As pessoas portadoras de deficiência intelectual não são apenas vítimas particularmente vulneráveis, mas são também vítimas que parecem esquecidas pelo sistema judicial. $\mathrm{O}$ seu acesso à justiça está longe de ser efetivo e diversos obstáculos já foram ultrapassados. Porém, há ainda um longo trabalho a percorrer porque os resultados alcançados ainda não se mostram satisfatórios. Julgamos que seja urgente e necessária uma atenção ao atual estado de coisas. Cremos que este fenómeno deve ser objeto de um amplo, aprofundado, multi e interdisciplinar debate, à semelhança do que tem sucedido, p. ex., com os crimes sexuais praticados contra crianças e mulheres. Sem procurar adiantar propostas de combate a esta criminalidade - que esperamos que surjam após os esforços encetados pela Presidência Portuguesa do Conselho da União Europeia - julgamos ter apontado alguns aspetos que podem, pelo menos, potenciar e assegurar um acesso à justiça que seja verdadeiramente efetivo e igualitário. 